\title{
What do hospital professionals report as helping in overcoming obstacles for ACP decision-making? A qualitative study
}

\author{
Birgit Vanderhaeghen ${ }^{1 *}$, Inge Bossuyt ${ }^{1}, J^{\prime}$ ohan Menten ${ }^{1,2}$ and Peter Rober, \\ ${ }^{1}$ Palliative Support Team, University Hospitals Leuven, B-3000 Leuven, Belgium \\ ${ }^{2}$ Department of Radiation-Oncology and Palliative Care, University Hospitals Leuven, B-3000 Leuven, Belgium \\ ${ }^{3}$ Context, UPC \& K.U. Leuven, B-3000 Leuven, Belgium \\ ${ }^{4}$ Department of Neurosciences, Medical School, KU Leuven - Institute for Family and Sexuality Studies, B-3000 Leuven, Belgium
}

\begin{abstract}
Background: Advance Care Planning (ACP) can be defined as an ongoing process of communication between patients and (in-) formal caregivers to help an individual identify, reflect upon, discuss, and express her or his values, beliefs, goals, and priorities to guide individual care and treatment decision making when nearing end of life. Studies suggest ACP is not well implemented in the hospital setting. This contrast sharply to the necessity of those conversations in hospitals: treatment decisions are made which potentially have a big impact on the patient's and families quality of life. AIMS: In order to facilitate the implementation of the ACP decision making process in hospital, it might be interesting to know what helps hospital professionals to overcome challenges.
\end{abstract}

Methods: 24 semi-structured interviews were taken from hospital physicians, nurses, psychologists and social workers and analyzed using content analysis based upon grounded theory principles.

Results: Participants reported that finding consensus about treatment and care was difficult. Furthermore, finding consensus on when to start decision making conversations with patients was difficult. Helping factors are multidisciplinary cooperation and strategies to convince one another, like the use of rhetoric's. Also, working closely together is also seen to be advantageous, because opinions can be checked and one can learn from more experienced colleagues.

Conclusion: This study gives an insight in how ACP is conducted in hospital practice and what is experienced as helping to overcome obstacles. Results can be used to facilitate implementation, for example by educating professionals.

\section{Introduction}

In recent history, calls for the strengthening of individual patient rights and participation in decision-making, have led to the development of the concept Advance Care Planning [1]. Advance Care Planning (ACP) can be defined as an ongoing process of communication between patients and (in-)formal caregivers to help an individual identify, reflect upon, discuss, and express her or his values, beliefs, goals, and priorities to guide individual care and treatment decision making when nearing end of life [2].

The ACP decision-making process is important in the hospital setting for many reasons. A first argument is that an important goal of ACP decision-making is guaranteeing continuation of care throughout the different care settings [3]. Second, in order to prevent hospital admissions for palliative patients, health services often focus on the implementation of ACP in the primary care setting and nursing homes [4-11]. However, still many palliative patients reside and die in the hospital setting [12-16]. When admitted to the hospital, palliative patients often experience the disease and treatment burden strongly. In these moments, questions concerning the meaning of treatment and disease may arise in patients. It is not a remote theoretical discussion that doesn't concern them [17-20]. In this setting, treatment decisions are made which potentially have a big impact on the palliative patient's daily life and might even cause or hasten death [21]. The biggest treatment decisions indeed concern hospital treatments (e.g. starting chemo therapy, stopping hemodialysis, placement of defibrillator ...) [22]. Furthermore, if the palliative patient loses competence in hospital, life-sustaining measures including cardiopulmonary resuscitation (CPR) are routinely implemented [23]. In the absence of advance directives (AD's) or medical instructions, this may lead to unwanted resuscitation [24]. Studies show that a lack of ACP discussions in hospital may lead to patients feeling overly optimistic about their prognosis, thereby choosing too aggressive medical treatment with a high burden of toxicity or side effects a high likelihood of an undesirable outcome $[25,26]$.

However, studies suggest ACP is not well implemented in this setting for palliative patients [10,27-30]. Implementation literature emphasizes the importance of a good understanding of experienced barriers and helpful factors [31-38]. In order to implement ACP more easily in hospital, it is valuable to have a better understanding of the ways in which hospital professionals deal with, and overcome these barriers [31]. In this article, we focus on what is seen as helpful

Correspondence to: Birgit Vanderhaeghe, Palliative Support Team, University Hospitals Leuven, B-3000 Leuven, Belgium, E-mail: birgit.vanderhaeghen@kuleuven.be

Received: April 06, 2017; Accepted: May 07, 2017; Published: May 10, 2017 
for hospital professionals to overcome experienced obstacles for ACP discussions. The research question of the study is: 'What is seen as helpful by hospital professionals to overcome challenges for the implementation of ACP conversations with patient and their families?'

\section{Methods}

\section{Design}

This study is part of a larger research project focused on understanding the difficulties of implementing ACP conversations in an hospital setting [39]. In this present study, an exploratory, qualitative methodological approach was chosen in order to study what is experienced as helpful to overcome barriers. Obtained data were studied with grounded theory [40-43].

\section{Recruitment of participants}

The study was conducted at the University Hospital UZ Leuven in Belgium (UZ Leuven 2016). This setting was chosen because of diversity in pathology and hyper-specialization of personnel. Recruited participants included physicians, nurses, psychologists and social workers, further in this paper referred to as 'participants'. These participants work in one of the three main care trajectories with palliative patients [45]: organ failure, oncology and gerontology. In total, 24 participants were included in the study (Table 1).

\section{Data collection}

The participants were interviewed in a room on the care unit where the hospital professional worked. Before the start of the interview, the participant was asked to sign an informed consent form and to fill out a brief questionnaire to gather some socio-demographic data (listed up in Table 1).

The researcher (first author) used an interview topic guide consisting of open questions. In line with grounded theory principles (Strauss \& Corbin 2015; Charmaz 2006), the researcher adapted the topic guide for every new interview (collection and analysis happened concurrent, see data analysis): every new interview brought new insights to the researcher, which she explored further, in the next interview.

\section{Data analysis}

The interviews were transcribed verbatim. After transcription, a summary of the interview and an overview of the main themes were made, following the QUAGOL approach for qualitative analysis [42]. Then, a line-by-line analysis of each interview was done using MAXQDA software. In that way, there was an oscillation between summarizing the main themes, and line-by-line detailed analysis.

The research group (2nd, 3rd and 4th author) came together regularly during the collection and analysis process. They supervised the analysis and gave suggestions for further directions of investigation.

Afterwards, three external auditors independently revised the hierarchical coding and categorization process. The researcher included their comments in the study.

\section{Ethics}

This research received no specific grant from any funding agency in the public, commercial, or not-for profit sectors. The Authors declare that there is no conflict of interest. Ethics approval for the study was given by the Ethics Committee UZ Leuven (S58196 / B322201525224 / I / U).

\section{Results}

The results are part of a larger study conducted by Vanderhaeghen et al. [39] in which data also led to the development of a model of ACP in hospital practice and to the unveiling of experienced barriers to ACP for hospital professionals. Both topics were described in an article [39]. In order to give a clear description of factors that are helpful in the implementation of ACP conversations, as they are experienced by professionals, we will briefly refer to some findings of the broader project concerning the barriers experienced by the professionals, if this seems necessary for clarification.

\section{Walking two roads simultaneously}

As shown in the previous study of Vanderhaeghen et al. [39], the participants reported that an important barrier to initiate ACP conversations is the absence of a consensus within a team about what the best moment is to start these conversations (see Figure 1 in appendix A). Many participants reported that they thought ACP conversations should take place if there is a slight chance that the patient will die [39]. They tended to start talking early in the disease trajectory. Participants who started talking about ACP late in the disease trajectory, reported to only initiate ACP conversations when treatment chances were low. They only saw one road; the road of real treatment chances. They didn't foresee different possible scenarios as they held on to the fact that there were still chances.

Participants who started talking about ACP early in the disease trajectory (seen as an essential part of ACP by patient organizations $[46,47])$, used the image of two roads that could be walked simultaneously. As a psychologist stated: "In my opinion, it is 'and... and...', both roads at the same time. A patient can get full treatment options and still have good chances to live long.". They thought that by explaining the other group of hospital professionals the metaphor of two roads, they could be thought that bad or good treatment chances are not the decisive factor in starting ACP.

\section{Finding consensus through communication within a team}

Participants reported that it is not clear when they have to stop treatments [39]. Participants have different grounds upon which they decide to stop treatments. One group of participants only considered the medical condition of the patient in this decision. Another group considered the resilience of patients and their families in order to carry the burden of the disease and treatments. Still another group focused on the wish of the patient as the most important ground upon which to base the decision to stop treatment. It was striking that the participants seemed to be unaware of these differences between one another. If it is not clear in a treatment team what the point of disagreement actually is, it may impede decision-making in the treatment team, as it makes reaching consensus more difficult [39].

It is not surprising in this context that communication is seen as the key facilitating factor in this process of finding consensus. According to our participants, in order to optimize communication in the team, the team should meet frequently. An important perceived facilitating vehicle for ACP is the weekly interdisciplinary team meeting on the ward. As a nurse stated: "The team meeting really is the place where I can discuss what I feel about what good care is now..., what we should do." In such weekly meetings, nurses, psychologists and social workers share psycho-social information about the patient, while physicians share medical information (e.g. prognosis). All interviewed participants perceive this information as helpful in their ongoing 
ACP communication with patient and family. This information is considered to be very important in order to make decisions. Also, some participants report that it is nice to know that decisions are back up by most team members.

Furthermore, some participants perceived a shared conceptual framework as important in communication. A head nurse stated: "Working with clear definitions, visible during the team meeting was helping, we understood one another better. E.g. when we talked about the 'palliative phase', we all meant the same.

\section{Coping with the hierarchy in decision-making}

As described in the previous article of Vanderhaeghen et al. [39], the four main actors in the treatment team (physicians, nonphysicians, psychologists and social workers, see Figure 1, appendix A) often passionately defend their convictions, because care and treatment decisions concern life and death themes. Participants report that during such discussions, there is an important power inequality between the actors. When physicians and non-physicians have different convictions, non-physicians have all kinds of strategies to convince physicians to stop treatment. E.g. they used rhetoric's, they gave the physician a vivid image of the suffering of the patient, they used the words of the patient to convince the physician, they picked their battles (cases that are worth fighting for), etc. Some physicians reported they try to involve non-physicians as much as possible in decision making, because they use their opinion as a check: "This really is the best decision, because team members have the same opinion." With this regards, participants also reported that working together closely on a care unit is helpful. They explained that by working side by side, it is possible to share with one another new information about the psychosocial and physical condition of the patient. Furthermore, it offered the possibility to check whether one's interpretation of the facts is shared by one's colleagues. For example, when the family asks to slow down the process of dying, the correctness of their request can be checked with colleagues.

Sometimes it is not possible to find consensus about treatment and care policy. This was experienced as very burdening by our participants. This was sometimes tangible during the interviews with participants; especially when there was anger about what was experienced as incorrect treatment decisions. One important difficulty reported by some participants, was the feeling of continuing dependency from one another; while sometimes there is no trust anymore. While professionals of the same care unit had to work together in many cases; having had to deal with treatment decisions of others with different judgments was a burden on the relationship of trust and collaboration. It seems that difficult cases may leave traces on the professional relationship. It makes working with patients, families and other team members more difficult.

\section{Finding meaning in care that is focused on the well-being of a patient}

Some participants reported that they found meaning in care that was focused on life prolongation; but not in palliative care. Creating time for palliative care was not seen as important for this group of participants [39]. This is an important barrier because it implies that professionals may sometimes not find meaning in care that is in line with the wishes of the patient. In contrast with these professionals, other participants report that for them contributing to the patient's life by focusing on quality of life, even if it is not focused on the prolongation of life, may be very meaningful. For those participants, palliative care is seen as an important aspect of patient care, where quality of the time left, is of utter importance. These participants reported that to them $\mathrm{ACP}$ is very important.

Some participants reported that personal life-events (e.g. a death in the family) or specific patient-cases made that they changed their point of view regarding what is good care: through such experiences they learned that contributing to the well-being of a patient can be as valuable as contributing to life prolongation. Other participants told us that they felt powerless towards the disease, but felt that they had a least some control over the well-being of the patient. A nurse told us: "I have the same kind of... no, even more satisfaction when I can wash a dying woman's hair, than when I'm able to learn a difficult technical action." The latter group is open to ACP conversations, because the essence of these conversations, to them, is understanding how the patient can feel better during treatments and care.

\section{A culture of patient-centeredness}

Some participants reported that the culture on a care-unit is helping or inhibiting the possibility to be focused on the wellbeing of the patient. On some wards, the head nurse installed a culture focused on care that is attuned to the personality of the patient. Within such a team culture, nurses who are focused on contributing to the patient's life by giving patient-centered care can develop this aspect in their care. $\mathrm{ACP}$ is seen as an important aid on these wards: it fits in the philosophy. Participants reported that such a team culture is an important facilitating factor when they want to engage in ACP conversations. They felt encouraged to know how the patient experiences care given and treatment received.

On other wards, there was a culture in which both the technical and the person focused care were valued and in which they are seen as complementary. On those wards, the nurses could specialize in care they felt more comfortable with: e.g. some nurses wanted to accompany physicians when they had ACP conversations with patients, while others preferred not to be part of decision-making and to focus on the treatment of the patient. As a physician said: "Some nurses are interested in being involved in the treatment and care policy, others want to stay away from it, they focus on the technical aspects of their job. Both are fine by me. Both are necessary."

\section{Experience with conversations about death}

An important facilitating factor for having ACP conversations was the experience of participants that patients and families experienced relief if they could talk about dying. According to some participants, it may be very helpful for inexperienced professionals to witness for the first time the positive reactions of patients while other (more experienced) colleagues have these kinds of conversations. Through learning of observing colleagues, they reported to have overcome their fear of addressing the topic of dying, which is essential in ACP conversations.

\section{Discussion}

While many studies in the ACP implementation literature only focus on experienced barriers to implementation [48], this study focuses on the resourcefulness and strengths of adopters of ACP decision making in hospital. Our findings show that ACP decision-making is seen to be the responsibility of the team of the care unit. The team decides when to start ACP, when to have the 'stop treatment' conversation, etcetera. Seeking consensus within a team is often challenging. Many reported helping factors are in fact ways to deal with this challenge and 
to find team consensus in decision-making. In line with some of the existing literature, our study shows that factors to overcome obstacles are mostly situated in communication with patients [23,49-51] or in personal attitudes of professionals [52-55].

An important finding of the study is that it is difficult to reach team consensus about the importance of timely engaging in the ACP process. Since the ACP decision-making process is not part of standard care, starting ACP depends upon the conviction of the hospital professionals that are involved. As a result, not all patients are offered the same option for timely engaging in the decision making process. There may be different strategies, to counter this inequality in patient care. One strategy might for instance be to teach head nurses that embedding a holistic view on patient care in the culture of the care unit is an important aid for hospital professionals to engage in ACP conversations.

It seems valuable to install milestones in the disease trajectory at which ACP can be executed. E.g. a team can agree that an oncology patient in stadium IV of the disease should have an ACP decisionmaking conversation. In this way, every patient gets the chance to reflect upon his or her care.

The results show that team cooperation might hold great opportunities for the facilitation of the ACP decision-making process. Team members can help each other. They can educate one another (e.g. learning through experience). Furthermore, they can function as sparring partners in decision-making and they can serve as a moral compass for one another.

\section{Acknowledgements}

The authors of this study want to thank the external auditors' dr. Alexander Verstaen, Ms. Eva Deslypere and dr. Let Dillen, who independently checked the coding process thoroughly. The authors also want to express their gratitude to the participants of the study for sharing their story.

\section{Appendix A}

Model of ACP communication in hospital, as described in the study of Vanderhaeghen et al. [39].

\section{References}

1. Strech D, Hirschberg I, Marckmann G (2013) Ethics in Public Health and Health Policy. Springer.

2. Teno JM, Hill TP, O'Connor MA (1994) Advance care planning. Priorities for ethical and empirical research. Hastings Cent Rep 24: S1. [Crossref]

3. Klee D (2008) The new national framework for NHS funded continuing care. $B r J$ Community Nurs 13: 38-40. [Crossref]

4. Mays N (2013) Evaluating the Labour Government's English NHS health system reforms: the 2008 Darzi reforms. J Health Serv Res Policy 18: 1-10. [Crossref]

5. Chow SW, Teno J, Clark M, Gozalo P, Trivedi A, et al. (2014) Director of nursing home perception of advanced care planning associated with increased burdensome transitions. J Am Geriatr Soc 62: S144.

6. Lamb G, Tappen R, Diaz S, Herndon L, Ouslander JG (2011) Avoidability of hospital transfers of nursing home residents: perspectives of frontline staff. J Am Geriatr Soc 59: 1665-1672. [Crossref]

7. Tena-Nelson R, Santos K, Weingast E, Amrhein S, Ouslander J, et al. (2012) Reducing potentially preventable hospital transfers: results from a thirty nursing home collaborative. J Am Med Dir Assoc 13: 651-656. [Crossref]

8. Wenger NS1, Citko J, O’Malley K, Diamant A, Lorenz K, et al. (2013) Implementation of Physician Orders for Life Sustaining Treatment in nursing homes in California: evaluation of a novel statewide dissemination mechanism. J Gen Intern Med 28: 51-57.
[Crossref]

9. Dellefield ME (2007) Implementation of the resident assessment instrument/minimum data set in the nursing home as organization: implications for quality improvement in RN clinical assessment. Geriatr Nurs 28: 377-386. [Crossref]

10. De Gendt C, Bilsen J, Stichele RV, Deliens L (2013) Advance care planning and dying in nursing homes in Flanders, Belgium: a nationwide survey. J Pain Symptom Manage 45: 223-234. [Crossref]

11. Towsley GL, Hirschman KB, Madden C (2015) Conversations about End of Life: Perspectives of Nursing Home Residents, Family, and Staff. J Palliat Med 18: 421428. [Crossref]

12. Cohen J, Bilsen J, Addington-Hall J, Löfmark R, Miccinesi G, et al. (2008) Populationbased study of dying in hospital in six European countries. Palliat Med 22: 702-710. [Crossref]

13. Richards M (2008) Department of Health. End of Life Care Strategy. Dep Heal London.

14. Van den Block L, Deschepper R, Drieskens K, et al. (2007) Hospitalisations at the end of life: using a sentinel surveillance network to study hospital use and associated patient, disease and healthcare factors. BMC Health Serv Res 7: 69. [Crossref]

15. Van den Block L, Pivodic L, Pardon K, Donker G, Miccinesi G, et al. (2015) Transitions between health care settings in the final three months of life in four EU countries. Eur J Public Health 25: 569-575. [Crossref]

16. Van Den Block, Bossuyt L, Van Casteren N, Viviane DL (2007) Het Sterfbed in België. Resultaten Ut de SENTI MELC Studie 2005-2006. Uitgeverij ASP nv.

17. Phua J, Kee AC, Tan A, Mukhopadhyay A, See KC, et al. (2011) End-of-life care in the general wards of a Singaporean hospital: an Asian perspective. J Palliat Med 14: 1296-1301. [Crossref]

18. Davis S, Low J, Vickerstaff V, Greenslade L, Hopkins K, et al. (2015) Understanding the care pathway of patients with cirrhosis in the last year of life. Gut 64: A467.

19. Bibic T, Saad S, George C (2013) Subcutaneous emphysema: A complication of cardiopulmonary resuscitation. J Am Geriatr Soc 61: S181-S182. [Crossref]

20. Gupta N, Thomas J (2014) Losing a battle but not the war: Insights into aveteran's preference for aggressive measures in advanced illness. J Gen Intern Med 29: S384.

21. Strom TJ, Naghavi AO, Trotti AM, Russell J, Kish JA, et al. (2017) Increased acute mortality with chemoradiotherapy for locally advanced head and neck cancer in patients 70years. J Geriatr Oncol 8: 50-55. [Crossref]

22. Drazen JM (2003) Decisions at the end of life. N Engl J Med 349: 1109-1110. [Crossref]

23. Bentur N (2008) The attitudes of physicians toward the new "Dying Patient Act" enacted in Israel. Am J Hosp Palliat Care 25: 361-365. [Crossref]

24. Seal M (2007) Patient advocacy and advance care planning in the acute hospital setting. Aust J Adv Nurs 24: 29-36. [Crossref]

25. Cohen A, Nirenberg A (2011) Current practices in advance care planning: implications for oncology nurses. Clin J Oncol Nurs 15: 547-553. [Crossref]

26. Ganti AK, Lee SJ, Vose JM, Devetten MP, Bociek RG, et al. (2007) Outcomes after hematopoietic stem-cell transplantation for hematologic malignancies in patients with or without advance care planning. J Clin Oncol 25: 5643-5648. [Crossref]

27. The SUPPORT Principal Investigators (1995) A controlled trial to improve care for seriously ill hospitalized patients. The study to understand prognoses and preferences for outcomes and risks of treatments (SUPPORT). JAMA 274:1591-1598. [Crossref]

28. Lovell A, Yates P (2014) Advance Care Planning in palliative care: a systematic literature review of the contextual factors influencing its uptake 2008-2012. Palliat Med 28: 1026-1035. [Crossref]

29. Meeussen K, Van den Block L, Echteld M, Bossuyt N, Bilsen J, et al. (2011) Advance care planning in Belgium and the Netherlands: A nationwide retrospective study via sentinel networks of general practitioners. J Pain Symptom Manage 42: 565-577. [Crossref]

30. Zhang B, Wright AA, Huskamp HA, Nilsson ME, Maciejewski ML, et al. (2009) Health care costs in the last week of life: associations with end-of-life conversations. Arch Intern Med 169: 480-488. [Crossref]

31. Grol R, Grimshaw J (2003) From best evidence to best practice: effective implementation of change in patients' care. Lancet 362: 1225-1230. [Crossref]

32. Pantoja T, Opiyo N, Ciapponi A, Dudley L, Gagnon MP, et al. Implementation strategies for health systems in low-income countries: an overview of systematic reviews (Protocol). Cochrane Database of Systematic Reviews 5. 
33. Sugiyama T, Zingmond D, Lorenz KA, Diamant A, O'Malley K, et al. (2013) Implementing physician orders for life-sustaining treatment in California hospitals: factors associated with adoption. J Am Geriatr Soc 61: 1337-1344. [Crossref]

34. Bender J, Russo J, Vovnoboy I, Rao S, Chippendale R (2015) Empowering internal medicine residents todiscussadvance care planning in primary care clinic. J Gen Intern Med 30: S494.

35. Allen SL, Davis KS, Rousseau PC, Iverson PJ, Mauldin PD, et al. (2015) Advanced Care Directives: Overcoming the Obstacles. J Grad Med Educ 7: 91-94. [Crossref]

36. Levy D, Strand J, McMahon GT (2015) Evaluating Residents' Readiness to Elicit Advance Care Plans. J Grad Med Educ 7: 364-368. [Crossref]

37. Paladino J, Bernacki R, Billings J, Block S (2015) Triggering advance care planning conversations in oncology and identifying barriers to these discussions. J Pain Symptom Manage 49: 445-446.

38. Zarrabi AJ, Rosenberg A, Brockway JP, Press MJ, Saigh O, et al. (2015) Physician attitudes regarding advance care planning for patients undergoing cancer treatment. $J$ Gen Intern Med 30: S66-S67.

39. Vanderhaeghen, B, Bossuyt, I, Opdebeeck, S, Menten, J, Rober P (2016) Towards hospital implementation of Advance Care Planning: shouldn't we think about involving hospital professionals? Under Review

40. Strauss AL, Corbin JM (1942) Basics of Qualitative Research: Techniques and Procedures for Developing Grounded Theory. (4thedtn). Thousand Oaks, California SAGE.

41. Charmaz K (2006) Constructing Grounded Theory: A Practical Guide through Qualitative Analysis. London Sage, London.

42. Dierckx de Casterlé B1, Gastmans C, Bryon E, Denier Y (2012) QUAGOL: a guide for qualitative data analysis. Int J Nurs Stud 49: 360-371. [Crossref]

43. Grossoehme DH1 (2014) Overview of qualitative research. $J$ Health Care Chaplain 20: 109-122. [Crossref]

44. https://www.uzleuven.be/over-ons.
45. Murray SA1, Kendall M, Boyd K, Sheikh A (2005) Illness trajectories and palliative care. $B M J$ 330: 1007-1011. [Crossref]

46. Al-Qurainy R, Collis E, Feuer D (2009) Dying in an acute hospital setting: the challenges and solutions. Int J Clin Prac 63: 508-515. [Crossref]

47. Smith TJ, Hillner BE, Kelly RJ, Cassel JB (2013) What makes the last few months of treatment so expensive? Eur J Cancer 49: S44.

48. Visser M, Deliens L, Houttekier D (2014) Physician-related barriers to communication and patient- and family-centred decision-making towards the end of life in intensive care: A systematic review. Crit Care 18: 604. [Crossref]

49. Ahluwalia SC, Bekelman DB, Huynh AK, Prendergast TJ, Shreve S, et al. (2015) Barriers and strategies to an iterative model of advance care planning communication. Am J Hosp Palliat Care 32: 817-823. [Crossref]

50. Boddy J, Chenoweth L, McLennan V, Daly M (2013) It's just too hard! Australian health care practitioner perspectives on barriers to advance care planning. Aust J Prim Health 19: 38-45. [Crossref]

51. Deep KS, Green SF, Griffith CH, Wilson JF (2007) Medical residents' perspectives on discussions of advanced directives: can prior experience affect how they approach patients? J Palliat Med 10: 712-720. [Crossref]

52. Bradley CT, Brasel KJ, Schwarze ML (2010) Physician attitudes regarding advance directives for high-risk surgical patients: a qualitative analysis. Surgery 148: 209-216. [Crossref]

53. Hajizadeh N, Uhler LM, Perez Figueroa RE (2015) Understanding patients' and doctors' attitudes about shared decision making for advance care planning. Health Expect 18: 2054-2065. [Crossref]

54. Buss MK, Alexander GC, Switzer GE, Arnold RM (2005) Assessing competence of residents to discuss end-of-life issues. J Palliat Med 8: 363-371. [Crossref]

55. Pfeil TA, Laryionava K, Reiter-Theil S, Hiddemann W, Winkler EC (2015) What keeps oncologists from addressing palliative care early on with incurable cancer patients? An active stance seems key. Oncologist 20: 56-61. [Crossref]

Copyright: (C2017 Vanderhaeghen B. This is an open-access article distributed under the terms of the Creative Commons Attribution License, which permits unrestricted use, distribution, and reproduction in any medium, provided the original author and source are credited. 